\title{
Determinants of fertility rate among women in Ghana and Nigeria: Implications for population growth and sustainable development
}

\author{
Innocent A. Ifelunini ${ }^{1}$, Samuel C. Ugwu ${ }^{2}$, Hycinth E. Ichoku' ${ }^{1}$, Ambrose N. Omeje ${ }^{1}$, \& \\ Emmanuella Ihim ${ }^{1}$
}

\author{
${ }^{1}$ Department of Economics, University of Nigeria, Nsukka \\ Enugu State Nigeria \\ ${ }^{2}$ Department of Public Administration and Local Government, \\ University of Nigeria, NSUKKA \\ Email: Innocent.ifelunini@unn.edu.ng
}

\begin{abstract}
Background: Some individual and community variables, such as rural population concentration, per capita income, life expectancy of men, female education, prevalence of contraceptive use among women, and composition of women education, have been revealed to determine the fertility rate among women globally. This study, in addition to these variables investigated the effect of remittances (a global environmental variable) on fertility among women in Nigeria and Ghana. The study also examined the trend in fertility among women in the two countries.

Data Source and Method: Macro data spanning 1962-2015, obtained from World Bank data portal-under the African Development Indicators (ADI) were analyzed using descriptive statistics (line graph) and random effect panel regression.

Results: Rural population concentration, per capita income, life expectancy of men, female education, prevalence of contraceptive use among women, and composition of women education are the key determinants of fertility among women in Ghana and Nigeria. Remittance inflows significantly increase fertility among women in Ghana and Nigeria. The fertility rate is declining more in Ghana than in Nigeria.

Conclusion: The results advocate the imperative for governments, policy makers, and development agencies to intensify their sensitization or enlightenment campaigns to ensure that remittances are being used productively and the rural areas adopt appropriate family planning in order to moderate population growth and facilitate the achievement of the Sustainable Development Goals
\end{abstract}

Keywords: fertility rate, women, population, Random effect, Sustainable Development

\section{Introduction}

There are more than 7 billion people on the planet earth, at the same time there is increasing decline in welfare and access to basic food. Report by Food and Agriculture Organization (FAO) in 2012 shows that of the 7 billion people on mother earth, about 870 million of them lack access to food. This has increased the imperative for the study of human fertility. One of the key challenges faced in the world today is the task of simultaneously improving the well-being of the large and growing population, and at the same time making sure there is sustainable use of essential but limited natural resources (United Nation Fund for Population Administration (UNFPA), 20I2). The challenge of striking this balance between sustainable development and population dynamics was recognized by the Rio Declaration and agreed at the United Nations Conference on the Environment and Development (UNCED), held in Rio de Janeiro in
1992 and the International conference in Cairo, Egypt in 1994. These twin declarations place humans at the center of development. The two declarations emphasized the need to promote human well-being and higher living standards. They however stressed on the need to do so in harmony with nature (United Nation Funds for Population Administration, 20I2). Therefore, considerations for the changing number of humans (population or fertility), characteristics, and distribution of human beings on the planet, must be at the core of any serious analysis of challenges and opportunities for achieving progress across the 5 sustainable development goals (SDGs) of people, planet, prosperity, peace, and partnership, which are anchored on end of poverty in all its forms everywhere, end of hunger, achievement of food security, and improved Nutrition.

It has become an increasingly global concern to ensure that developing nations achieve a 
demographic dividend, which entails the achievement of economic growth that accrues as countries experience lower fertility rate (Roger and Stephenson, 2017; Canning, 2015). The central focus in achieving a demographic dividend is achieving reductions in fertility which has profound implications for sustainable development goals. Fertility has been implicated as one of the greatest sources of imbalance between national policies and individual goals.

World Bank (20I4) had estimated that I.4billion people will be living in sub-Saharan Africa in the year 2030 with an average age of 20 years. It is also expected that about I billion people will be added to the world population in 2030. While the World Bank opined that population of countries in Europe and Asia is expected to maintain existing level or fall in the coming decade, much of the anticipated growth in world population is expected to occur in countries in South Asia and sub-Saharan Africa, particularly in populous countries where fertility remains relatively high, for example Pa kistan, Nigeria, and the northern states of India. The link between population growth and environmental degradation through the Environmental Kuznets Curve is critical for realising SDGs.

The decreasing per capita income of Nigeria and Ghana, two leading West African States in the SubSaharan Africa, occasioned by daunting economic challenges, has made the fertility position in these countries a source of policy concern. In spite of the enormous natural resources in these countries, the large proportion of the citizens live in extreme poverty. Despite efforts by government, fertility continues to grow at estimated $2.3 \%$ growth rate annually (Olatoregun, 2014) and at the same time, the level of mortality decreases significantly in response to the advances in medicine and nutritional intakes. Consequently, the quality of the population in terms of education, jobs, medical provision, ratio of policemen to citizens, among others, are negatively affected. Thus, high fertility rate and rapid population growth exert negative influences where there is poor economic and social development (Fagbamigbe et al, 20|4).

Although Nigeria and Ghana fertility rates and patterns have been investigated in recent times (Wusu \& Isiugo-Abanihe, 2018; Odimegu \&Adedini, 2017; Alaba, Olubusoye \& Olaomi, 2017; Adebowale, 2016; Agyei-Mensah and Owoo, 2015; Udomboso, Amoateng \& Doegah, 20I5; Odimegu \& Adedini, 20/4), most of the studies are cross sectional (using Demographic and Health Survey) and could not give the trend in event. Another shortcoming of these studies is that using crosssectional or household data makes it difficult to use the result of the studies for forecasting and prediction. Hence, the current study went beyond cross-sectional or household data to improve forecasting and prediction. Furthermore, this study used fixed effect framework which has the advantage of handling the problem of multicollinearity and heteroscedasticity that may bedevil cross country model. One policy concern that remains largely unaddressed by previous studies on fertility rate in Ghana and Nigeria is the influence of remittances inflow on fertility rate. Emerging studies such as Naufal (20I5) are beginning to look at the influence of remittance inflows (global economic environment) on fertility; though household-specifics, when considered at the macro level/country-wide scale, could have significant policy implications. It therefore makes it expedient to understand the nexus between remittances inflow and fertility rate in Ghana and Nigeria. Against the backdrop of the issues raised, this study focusses on macro-level analysis (time series) of the determinants of fertility among women in Ghana and Nigeria. The study also examined: the trend in fertility in Ghana and Nigeria; the influence of remittance inflows on fertility in Ghana and Nigeria; and implications of fertility rate for sustainable development goal. The key hypothesis tested in this study was that individual, community, and global economic environment variables/factors do not significantly determine fertility rate among women in Nigeria and Ghana.

\section{Literature review \\ Conceptual issues}

The concept of general fertility rate (also called the fertility rate) is the number of live births per 1,000 women ages 15 to 49 in a given year (Population Reference Bureau (PRB), 20II). General fertility rate has been adjudged to be somewhat a more refined measure than the birth rate because of its inherent characteristics of relating births to the age-sex group at risk of giving birth (usually defined as women ages I5 to 49). This feature provides the advantage of eradicating distortions that might arise because of different age and sex distributions among populations (PRB, 20II). Thus, the general fertility rate is a better basis to compare fertility levels among populations than are changes in the crude birth rate. Fertility as a concept differs from fecundity which depicts the physiological capability of women to reproduce. Fertility is a function of some basic variables, which, in turn, are also affected by great many other factors, such as social, cultural, economic, environmental, and health factors. Total fertility rate (TFR) therefore, is the average number of children that would be born to a woman by the time she ended childbearing if she were to pass through all her childbearing years 
conforming to the age-specific fertility rates of a given years.

\section{Theoretical framework and empirical literature}

The main theory underpinning this study is the economic theory of fertility. The theory derives from the recent recognition of the need to extend economic theory to integrate socioeconomic and structural and environmental variables in the analysis of fertility with unified framework (Willis, 1974). The theory was heavily influenced by earlier views of Becker (1960), and further influenced by models of fertility, child quality, and related aspects of household behavior by Schultz (1973), and Sanderson and Willis (197I). The main thesis of the economic theory of fertility is that fertility is a function of individual level variables (Hirschman \& Young, 2000). Such individual variables include individual education, income, occupation, etc (Odimegwu \& Adedini, 2017).

One effective way to enhance policy towards promoting sustainable development goals is to identify the factors or variables that affect fertility, and intervene with the appropriate policy mix. Using the demographic and health survey data 2008, Fagbamigbe et al (20l4) found that education, age at first marriage, marital status, urban-rural residence, wealth index, and use of contraception, were the main factors that influence high fertility levels. Religion and cultural factors, fertility attitude among women, female education attainment, and child mortality, have been identified as factors that affect fertility both at the national and regional levels (Wusu \& Isiugo-Abanihe, 2018; Agyei-Menasah \& Owoo, 20I5). Udomboso et al (20I5) noted that education attainment, exposure to media, and visitation to health facility, positively influence the use of contraceptives; while Odimegwu \& Adedini (2017) identified residence in socioeconomically disadvantaged region, rural residence, community with high family size norm, as community factors that influence fertility in Africa. Similarly, Alaba, Olubusoye \& Olaomi (2017) identified age at first birth, and rural residence, as factors that significantly affect fertility in Nigeria. A study on determinants of fertility, by Amoo (20I I), found that over one half of the women of childbearing age desired to have between four and six children, while $39.5 \%$ desired to have above six children. Similarly, Ushie, Ogaboh, Olumodeji \& Attah (20II) revealed that age at among women in Nigeria and Ghana.To identify the determinants of fertility rates among women in Nigeria and Ghana, the panel random and fixed effect models were looked at. In order to select the appropriate model that best identifies the determinants of fertility rates among women in the marital union, contraceptive use, and education level, significantly determine fertility differential between rural and urban communities in Cross River State of Nigeria.

One observed shortcoming of the studies reviewed above is that they are mostly crosssectional (using mainly Demographic and Health Survey) and could not give the trend in event. The cross-sectional nature of these studies makes them unamenable for forecasting and prediction. These studies also downplayed the role of remittances (global economic environment) on fertility, an area that is calling for research attention given the volume of remittances inflow into the African continent in recent decade and evidence from other climes. This study will bring in some value by filling these identified gaps.

\section{Data and methods}

The data for the study is long (time) series collected from the World Bank data portal for African countries - under the African Development Indicators (ADI) spanning 1962-to-20I5. The World Bank Development Indicator data base compiles data at the country level for countries of the world. For the sake of this study, data for two countries, Nigeria and Ghana, from 1962 to 2015, were sieved out. The World Development Indicators (WDI) data set was chosen because it possesses some interesting features that are policy appealing. For instance, the WDI provides high quality cross-country data and also includes indicators that help to measure the targets of the Sustainable Development Goals (SDGs), and these enhance the measurement of trends in development indicators. The exogenous variables used for the study can be classified according to existing literature to include individual level, community level, and global economic environment data. For the individual level data, the variables used include: women education, per capita income, life expectancy, and contraceptive use. In terms of the community level data, the variable used was the rural concentration of population. Furthermore, remittances inflow which proxy the global economic environment was used as one of the exogenous variables.

\section{Data analysis}

The simple descriptive statistics (line graphs) was adopted to examine the trend in fertility study countries, the study applied the Hausman selection test. The Hausman specification test usually helps to select the more appropriate model between fixed and random effect in a panel regression model. Based on the Hausman test, the study adopted the random effect model. Nevertheless, before the fixed 
effect model specification, we adapted a modified Bongaarts et al's model of proximate determinants of fertility (Bongaarts et al 1984) to specify the model as:

$$
C B R_{i}=\alpha_{0}+\alpha_{1} R U P_{i}+\alpha_{2} P C I_{i}+\alpha_{3} L E X_{i}+\alpha_{4} E D U_{i}+\alpha_{5} C O N_{i}+\alpha_{6} F P C_{i}+\alpha_{7} R E M_{i}+\mu_{i}----(1)
$$

where;

$\mathrm{CBR}=$ crude birth rate

RUP $=$ rural concentration of household population

$\mathrm{PCl}=$ per capita income

LEX $=$ life expectancy of male population

$\mathrm{EDU}=$ female education

$\mathrm{CON}=$ the prevalence use of contraceptives among women

$\mathrm{FPC}=$ female population composition

REM $=$ Remittances inflow

$f=$ functional notation

$a_{0}=$ the constant term

$\mathrm{a}_{\mathrm{j}}=$ parameter estimates, $\mathrm{j}=\mathrm{I}, 2, \ldots, 7$

$\mathrm{i}=$ each country specific variable; Ghana and Nigeria

$\mathrm{u}_{\mathrm{j}}=$ the error term

Hence, the fixed effect model used by the study is defined according to the following specification:

$$
Y_{i t}=\alpha_{i}+\beta^{\prime} X_{i t}+\varepsilon_{i t}
$$

Where $i=I \ldots \ldots . N ; t=I \ldots \ldots . . N$

Yt indicates the dependent variable (in this case, crude birth rate), while $X t$ represents the vector of $k$ explanatory variables (rural concentration of household population (RUP), Per capita income $(\mathrm{PCl})$, life expectancy (LEX) of male population, prevalence use of contraceptives among women $(\mathrm{CON})$, female population composition (FPC), Education of female population (EDU), and Remittance inflow (REM)). $\alpha_{\mathrm{j}}=\mathrm{I} \ldots . \mathrm{N}$ are constant coefficients specific to each country. Their presence assumes that differences across the considered countries appear by means of differences in the constant term. The individual coefficients are estimated together with the vector of coefficients, $\beta$.

In order to validate the fixed effect specification, the question is to prove, according to the empirical application, that the individual coefficients $\alpha_{\mathrm{j}}, \mathrm{i}=\mathrm{I}$...N are not all equal as stated in the hypothesis at the introduction section (individual, community, and global economic environment variable/factors do not significantly determine fertility rate among women in Nigeria and Ghana).

The assumption made about the intercept variable $\left(\alpha_{j}\right)$ had implications for the consistency and efficiency properties of estimates of $\beta^{\prime}$ in equation (2). In the same equation, the group-specific term reflects idiosyncratic preferences or characteristics of each country. If the country specific effect is assumed to be constant (but allowed to differ across units) a fixed effects (FE) model is generated. Assuming heterogeneity across units in equation (2) implies that the effect of all omitted variables is the same for a given cross-sectional/country units through time but varies across cross-sectional/country units for a given point in time. Wald chi2 was used to test that all the coefficients are statistically significant while the intraclass correlation was used to test for variance across country population.

\section{Results}

Figure $\mathrm{I}$ indicates that the fertility rate (crude birth rate) in Nigeria is above that of Ghana. In 1962, both Nigeria and Ghana maintained similar fertility rateS, but as the years went by, an evident gap has grown between 1968 and 2015. The implication here is that the fertility rate in Ghana trended below that of Nigeria. This can be seen in Figure I below: 
Tables and figure showing results

\section{Fig.1: Trend Analysis of Crude Birth Rates Between Ghana and Nigeria from 1962 to 2015}

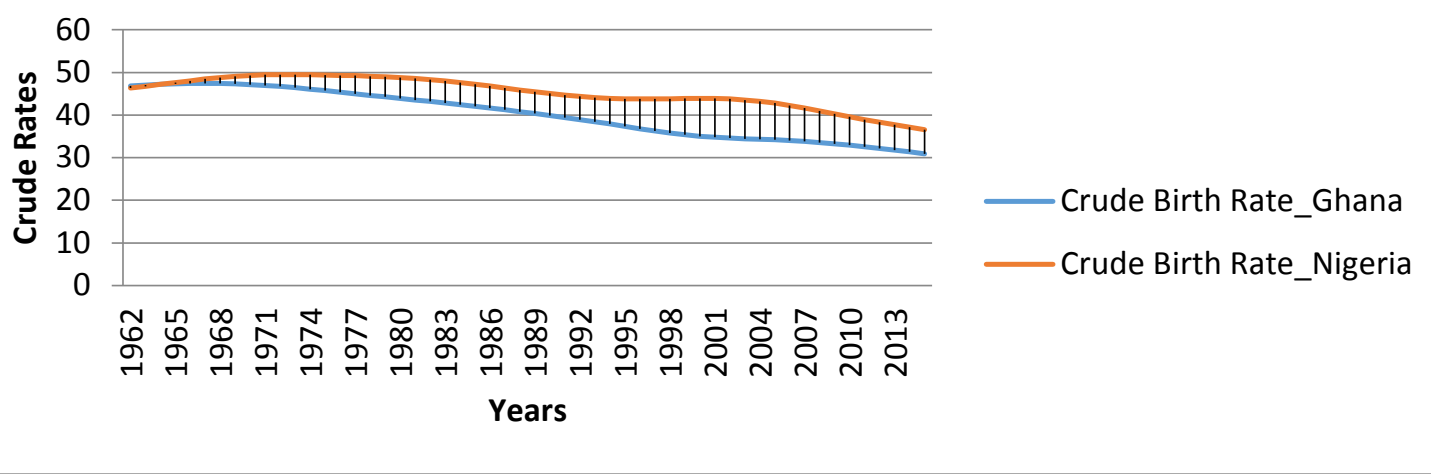

In order to effectively identify the determinants of fertility rates among women in Nigeria and Ghana, the panel random and fixed effect models were looked at. However, in order to select the appropriate model that best identifies the

Table I: Results of random effectt model

\begin{tabular}{lllll}
$\begin{array}{l}\text { birth } \\
\text { rate }\end{array}$ & Coef. & Std. Err. & $\mathbf{t}$ & $\mathbf{P}>|\mathbf{t}|$ \\
Rup & .0035008 & .0005607 & 6.24 & 0.000 \\
\hline Pci & .0033318 & .0006121 & 5.44 & 0.000 \\
\hline Lex & -.7594071 & .0510349 & - & 0.000 \\
& & & 14.00 & \\
\hline Edu & -.0837296 & .0206668 & -4.05 & 0.000 \\
\hline Cont & -.0858742 & .0659541 & -1.30 & 0.193 \\
\hline Fpc & .7344919 & .1048332 & 7.01 & 0.000 \\
\hline Rem & .000278 & .0000714 & 3.90 & \\
_cons & 44.83475 & 5.084748 & 8.82 & 0.000 \\
\hline sigma_u & 0 & & & \\
\hline sigma_e & 1.9375868 & & & \\
\hline
\end{tabular}

sigma_e 1.9375868

\begin{tabular}{ll} 
Rho & 0 \\
Wald & 715.49 \\
Chi $^{2}$ & \\
\hline
\end{tabular}

Table I shows that the errors, $u_{-} i$, are uncorrelated with the regressors, $X$, in the random effects model (that is; corr $\left(u_{-} i, X\right)=0$ ). In addition, the Wald chi2 test indicates that all the coefficients in the model are different from zero (that is; Wald chi2(6) $=715.49$ hence, it is statistically significant). More so, the probability of Chi2 is also less than 0.05 (that is; Prob $>$ chi2 $=0.0000<0.05$ ) thereby, agreeing with the Wald chi2 test. Hence, the model is good and as a result, has a good fit. However, the intra-class determinants of fertility rates among women in Nigeria and Ghana, the study applied the Hausman selection test. The summary results of the random and fixed effect models, as well as the Hausmann test, can be seen in Tables I, 2, and 3 respectively. correlation (rho) indicated that about $0 \%$ of the variance is due to differences across country population.

In order to select the appropriate model (random or fixed effect model) that best identifies the determinants of fertility rates among women in Nigeria and Ghana, the study also looked at the fixed effect model before applying the Hausman selection test. Hence, the fixed effect model is summarized in Table 2 below: 
Table 2: Summary results of fixed effect model

\begin{tabular}{lllll} 
birth rate & Coef. & Std. Err. & $\mathbf{t}$ & $\mathbf{P}>|\mathbf{t}|$ \\
\hline Rup & .0030977 & .0011305 & 2.74 & 0.007 \\
\hline Pci & -.0031716 & .0007278 & -4.36 & 0.000 \\
\hline Lex & -.7861688 & .0828402 & -9.49 & 0.000 \\
\hline Edu & .0797664 & .0228822 & 2.49 & 0.001 \\
\hline Contrcpt & .0643618 & .0844018 & 0.76 & 0.448 \\
\hline Fpc & .702337 & .1311397 & 5.36 & 0.000 \\
\hline Rem & .0002593 & .0000849 & 3.06 & 0.003 \\
\hline cons & 47.69536 & 8.629736 & 5.53 & 0.000 \\
\hline sigma_u & .55111031 & & & \\
\hline sigma_e & 1.9375868 & & & \\
\hline Rho & .07484603 & & & \\
\hline corr(u_i, Xb) & -0.5684 & & & \\
\hline F (7,99) & 74.59 & & & \\
\hline F(prob) & 0.000 & & & \\
\hline
\end{tabular}

The result in table 2 suggests that the errors, ui, are correlated with the regressors in the fixed effects model. More so, the F-test indicates that all the coefficients in the model are different from zero.

Hence, the model is good and as a result, has a good fit. However, the intra-class correlation (rho) indicates that about $79.29 \%$ of the variances are due to differences across panels. As indicated in the methodological section, the essence is to present the random and fixed effect models and then use the Hausman selection test to select the appropriate model to be interpreted. The summary of the Hausman selection test is presented in Table 3 below:

Table 3: Summary results of the hausman model selection test

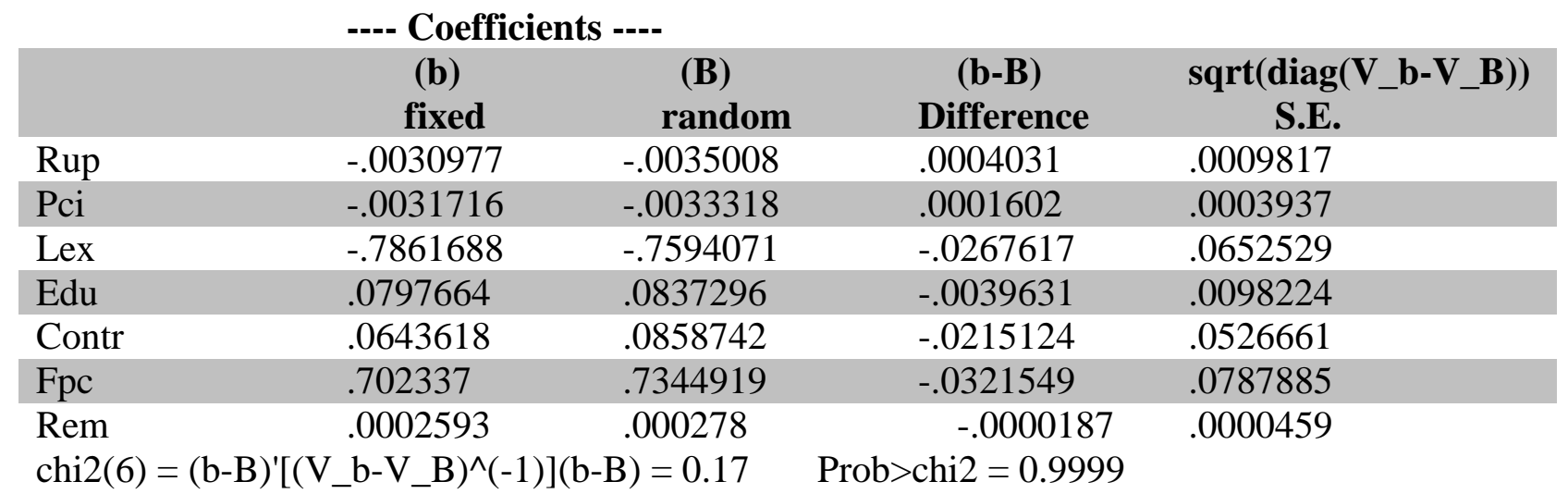

From the summary of results of the Hausman test conducted on the two models, as shown in Table 3, where Prob $>$ chi2 is greater than 0.05 (Prob $>$ chi2 $=0.9999>0.05)$, the study adopted the random effect model as the best model that identifies the determinants of fertility rates among women in Nigeria and Ghana. Thus, the random effect model is consistent and efficient under $\mathrm{HI}$; that the preferred model is random effect model. The study therefore http://aps.journals.ac.za switched to the random effect model for the interpretation of results and other tests.

\section{Discussion}

The results of the random effect model presented in Table I indicate that concentration of rural population (rup) significantly increases the fertility rate in Nigeria and Ghana. This result is not surprising since it is expected that the higher the rural 
population, the higher the tendency of a rise in fertility. Again, it is believed that rural dwellers often times marry at a much younger age than the urban dwellers as such conforms to the result. This study tends to corroborate Ushie, Ogaboh, Olumodeji \& Attah (20II) which revealed that age at marital union determines fertility differential between urban and rural communities in Cross River State, Nigeria. Again, many of the rural dwellers see children as insurance/ personal labour force in their traditional farming business.

An increase in per capita income would result in insignificant increase in the fertility rate by about 0.0033 units. This result is not surprising since it is expected that higher income per capita in Nigeria and Ghana will lead to higher rate of fertility. This finding agrees with earlier findings by Becker (1960) who argued for positive relationship between income and fertility by viewing children as consumer goods that are competing with alternative goods, as parents attempt to maximize their utility or satisfaction. Again, recent studies established that increase in income while decreasing fertility in developed countries, will lead to opposite results in developing or poor countries (Vandenbroucke, 2016). The author buttressed his finding by listing some of the reasons for such position, such as children requiring more education to be successful in developed countries unlike the poor countries. Also children are like insurance at old age. Moreover, other studies, such as Elliot and Inyong (2016) found an inverse relationship between income and fertility across countries.

Life expectancy of men has also shown to have negative and significant effect on fertility rate in both Nigeria and Ghana. The implication here is that the higher the life expectancy, the lower the number of children that will be born of women. This result looks seemingly counter-intuitive as regards developing countries since men constitute a critical factor in fertility. One reason for this result may be that men are gradually being conscious of the fact that modernization has reduced the notion of children being seen as insurance at old age; and also the cost of training children has also gone up (economic factor).

Furthermore, female education has been revealed to significantly influence fertility in Nigeria and Ghana. For instance, the result of the study shows that increase in the level of education of women significantly reduces the fertility of women. This result also agrees with earlier studies (Udomboso et al, 2015; Fagbamigbe et al, 2014).

The prevalence of contraceptive among women in Nigeria and Ghana has shown to reduce fertility rate. This is expected as increase in the use of $4|3|$ contraceptives is expected to reduce the number of children to be born. This is also in line with the study by Boadu (2002) and Ushie, Ogaboh, Olumodeji \& Attah (20II) that the use of contraceptives has positive influence on the reduction of fertility among Ghana women. The results also indicate that when there is a rise in the composition female population per thousand of the population in Nigeria and Ghana, fertility rate increases significantly by about 0.734 . The result is not surprising since the implication of the result here is that the higher the composition of female population, the higher fertility rate tends to rise in both countries.

One important finding of the study is that remittances inflow increased the fertility rate in Nigeria and Ghana within the study period. This has implication for policy intervention. This implies that households who receive remittances see children as form of investment for future financial support and therefore tend to increase fertility as remittances inflow increase (see Naufal, 20I5).

Finally, controlling for the random effect characteristics of all the women in both Nigeria and Ghana (cons), the results indicate that there is a significant rise in fertility in both countries by about 44.83 units.

\section{Conclusion/policy implications}

The paper examined the trend and determinants of fertility in a two-country economic space, Nigeria and Ghana, using random effect panel regression. Using some individual, community, and global economic environment variables, the result revealed that rural population concentration, per capita income, life expectancy of men, female education, prevalence of contraceptive use among women, and composition of women education, are the key determinants of fertility among women in Ghana and Nigeria. While all the variables meet their a priori expectations, only life expectancy of men produced somewhat counterintuitive result which suggests that life expectancy of men influenced fertility decision in an opposite manner within the period under study. These results have policy implications more especially as literature has established some kind of link between fertility or even population, and some components of the SDGs.

One instructive revelation from this work is that remittance inflows, a proxy for global economic environment, increases fertility. This suggests that remittance inflow has induced remittance recipients to increase their fertility behaviour with the assurance that children will provide financial support in future. Again, the finding that the rural population has high tendency to have more children and affluence is associated with high fertility. This perhaps could partially account for the high poverty incidence 
in Ghana and Nigeria, especially in Nigeria where there is poverty circle-where poor men have larger families with poor education and welfare implications. This has spiral effects on production, energy consumption, and even climate change. This has serious implication for Sustainable Development Goals. This means that governments, policy makers, and development agencies have to intensify their sensitization or enlightenment in the rural areas to ensure that family planning is adopted and effectively implemented. Instructively, the fertility trend in Ghana and Nigeria shows that the benefits of birth control are less known and addressed in Nigeria unlike what is obtainable in Ghana. The positive relationship between remittances inflow and fertility provokes the imperative to increase the momentum in the sensitization of women in the more productive use of remittances as means of human capital investment. Again, more efforts should be geared towards re-orientation of women, especially the educated ones, on the need and importance of compliance with fertility advice. This is very critical as African countries strive towards meeting the SDGs.

\section{Reference}

Agyei-Mensah, S and Owoo, N.S. 20I5. Explaining Regional Fertility Variations in Ghana. J.Pop Research, 32:157-I72

Alaba, O.O, Olubusoye, O.E \& Olaomi, J.O. 2017. Spatial Patterns and Determinants of Fertility levels among women of childbearing age in Nigeria. South Africa Family Practice 59(4): I43147

Amoo Emmanuel Olagunju (20I I). Trends and proximate determinants of fertility decline in Nigeria. Global Journal of Applied, Management and Social Sciences, Vol. 2

Becker, G.S. 1960. "An Economic Analysis of Fertility," in Demographic and Economic Change in Developed Countries, Universities-National Bureau of Economic Research, Princeton, NJ: Princeton University Press, 209-3I

Bongaarts, J., Frank, O. and Lesthaeghe, R. 1984. The proximate determinants of fertility in sub-Saharan Africa. Population and Development Review 10(3):5 I I-537

Canning, D. 2015. Population Change and the Demographic Dividend in Sub-Saharan Africa.

Presentation to the Committee on Population Workshop on Recent Trends in Fertility in Sub-

Saharan Africa, June 15-16, National Academy of Sciences, Washington, DC.

Food and Agriculture Organization. 2012. "The State of Food Insecurity in the World 2012" http://www.fao.org/docrep/016/i3027e/i3027e00. htm
Hirschman, C. \& Young, Y-J. 2000. Social context and fertility decline in Southeast Asia: 1968-70 to 1988-90. Population and Development Review 26, II-39

Inyong, S. and Elliott, C. 2016. "Change and prediction of income and fertility rates across countries". Cogent Economics \& Finance, 4,(I)

Naufal, G. 2015. Impact of Remittances on Fertility. IZA World of Labour. Evidence based

policy making.

Odimegwu, C and Adedini, S.A. 2017. The Role of Community Structure in Shaping African Fertility Pattern: Evidence form Demographic and Health Surveys. J.Biosoc. Sci. (49) S46-S6I

Odimegwu, C. \& Adedini, S. A. 2014. Gender dynamics and fertility transition in sub-Saharan Africa. Gender and Behaviour I2(4), 5964-5983.

Olatoregun, O, Fagbamigbe, A.F, Akinyemi, O.J, Oyindamola, B.Y \& Bamgboye, E.A. 20I4. A

Comparative Analysis of Fertility Differentials in Ghana and Nigeria. Afr J Reprod Health 18(3):3647

Haupt, A., Kane, T. T.\& Haub, C. 20II. PRB's Population Handbook, 6th Edition

Rogers, E and Stephenson, R. 2017. "Examining Temporal Shift in the Proximate Determinants

of Fertility in Low-and Middle-Income Countries. J.Biosoc. Sci. ppl-18

Sanderson, W. and Willis, R. 197I."Economic Models of Fertility: Some Examples and Implications," An Annual Report (Washington, D.C, National Bureau of Economic Research)

Schultz, T. P. 1973. "A preliminary survey of economic analyses of fertility." The American Economic Review 63, No. 2: 7I-78.

Udomboso, C.G, Amoateng, A.Y \& Doegah, P.T. 2015. Bio-social correlates of intention to use or not to use contraception: The case of Ghana and Nigeria. African Population Studies, Vol 29, No.2 208I-2I00

United Nation Fund for Population Administration (20I2). Population Matters for Sustainable

Development. www.unfpa.org/public/cache/once/home/publicati on

Ushie, M.A, Agba, A.M, Ogaboh,, Olumodeji, E. and Attah, F. 201 I. "Socio-cultural and

Economic Determinants of fertility differentials in rural and Urban Cross River State, Nigeria".

Journal of Geography \& Regional Planning 4, (7): 383391

Vandenbroucke, G. 2016. The link between Fertility and Income. https://www.stlouisfed.org/on

the-economy/2016/december/link-fertility-income Willis, R.J. 1974. "Economic Theory of Fertility Behavior," NBER Chapters,in: Economics of the 
African Population Studies Vol 32, No 2, (Supp. 2), Sept. 2018

Family: Marriage, Children, and Human Capital, pages 25-80 National Bureau of Economic Research, Inc

World Bank 2014. Youth employment in sub-Saharan Africa. New York: World Bank, Africa
Development Forum

Wusu, $\mathrm{O}$ and Isiugo-Abanihe, U.C. 20I8. Consistency of the Effects of Female Education on Fertility across the North-South Demographic Divide in Nigeria. J.Biosoc. Sci. ppl-16 